\title{
Molecular dissection of human oncostatin M-mediated signal transductions through site-directed mutagenesis
}

\author{
HAIYAN LIU ${ }^{*}$, CRISTINA FENOLLAR-FERRER $^{2 *}$, AIQIN CAO ${ }^{1,3}$, \\ CLAUDIO ANSELMI ${ }^{2}$, PAOLO CARLONI ${ }^{2,4}$ and JINGWEN LIU ${ }^{1}$ \\ ${ }^{1}$ Department of Veterans Affairs Palo Alto Health Care System, Palo Alto, CA 94304, USA; \\ ${ }^{2}$ SISSA/ISAS International School for Advanced Studies, Via Beirut 2-4, I-34014 Trieste, \\ Italy; ${ }^{3}$ Division of Endocrinology, Stanford University, Stanford, CA 94305, USA; \\ ${ }^{4}$ INFM-DEMOCTRITOS and IIT-SISSA Unit, Via Beirut 2-4, I-34014 Trieste, Italy
}

Received October 6, 2008; Accepted November 3, 2008

DOI: 10.3892/ijmm_00000113

\begin{abstract}
The binding of oncostatin M (OM) to type I and type II receptor complexes elicits various biological responses by activating MEK/ERK and JAK/STAT signaling pathways. Some OM effects are clinically desirable such as reducing hyperlipidemia through the activation of hepatic LDL receptor transcription, a downstream event of ERK activation. The OM pro-inflammatory responses via induction of acute phase protein gene expression have been associated with STAT activation. In this study, by conducting site-directed mutagenesis, bioassays and molecular modeling we have defined $4 \mathrm{OM}$ residues that are differently involved in the activation of ERK or STAT signaling pathway in HepG2 cells. We show that mutation of Lys 163 to alanine totally abolished OMmediated signaling, possibly because such mutation causes the disruption of a stabilizing $\mathrm{H}$-bond pattern at the OM interface with receptors. G120A mutation equally impaired activations of ERK and STAT signaling pathways also by impairing the $\mathrm{OM} /$ cognate protein interactions. Interestingly, mutations of Gln20 and Asn 123 differentially affected OM signaling
\end{abstract}

Correspondence to: Dr Jingwen Liu, VA Palo Alto Health Care System, 3801 Miranda Avenue, Palo Alto, CA 94304, USA

E-mail: jingwen.liu@med.va.gov

${ }^{*}$ Contributed equally

Abbreviations: CBM, cytokine-binding module; CM, conditioned medium; ERK, extracellular signal-regulated kinase; FGB, fibrinogen $B$; IL-6, interleukin-6; LDLR, low-density lipoprotein receptor; LIF, leukemia inhibitory factor; LIFR, LIF receptor; MD, molecular dynamics; OM, oncostatin M; OSMR $\beta$, OSM receptor $\beta$ subunit; SI, sequence identity; STAT, signal transducer and activator of transcription; wt, wild-type

Key words: oncostatin M, oncostatin M receptors, site-directed mutagenesis, signal transduction, gene expression, molecular modeling through the two pathways. Q20A and N123A retained strong activity in inducing ERK phosphorylation but they showed diminished ability in activating STAT1 and STAT3. We further showed that mutations at Gln20 and Asn123 reduced $\mathrm{OM}$ induction of inflammatory gene fibrinogen- $\beta$ to a greater extent than that of LDL receptor gene. The mutation of Asn123 is directly related to local structural modification at site 3 of OM. Collectively these results provide a structural basis of OM-mediated signaling and suggest a potential to improve OM therapeutic properties via structural modification.

\section{Introduction}

Human oncostatin M (OM), produced by T cells, monocytes, and neutrophils, belongs to the interleukin-6 (IL-6) family of cytokine that includes IL-6, IL-11, leukemia inhibitory factor (LIF), ciliary neurotrophic factor, cardiotrophin-1 and neutrophin-1/B-cell-stimulating factor-3. One prominent feature of the IL- 6 cytokine family is the common use of transmembrane protein gp130 as a shared signal transducing chain of various receptor complexes among family members (1-5), which explains in part the overlapping effects of these cytokines.

The biological responses of OM are complex and involve in different aspects of cell functions such as cell growth, differentiation, immune response, inflammation, neural development, hematopoiesis, liver regeneration and repair and regulation of lipid metabolism. Some of these effects are clinically desirable. In particular, the beneficial effects of OM in lipid metabolism open up a possibility for its therapeutic application. Unfortunately, this potential is hindered by other undesired effects of OM such as induction of inflammatory response (6). Thus, there is currently a great interest in understanding the molecular and cellular basis of such OM responses and in particular on the role of $\mathrm{OM}$ for the lipid metabolism.

It is known that $\mathrm{OM}$ responses are elicited specifically by formation of two high affinity heterodimeric receptor complexes, namely type I and type II $(7,8)$. The type I OM receptor is comprised of gp130 and LIF receptor (LIFR) $(9,10)$; the type II receptor complex consists of gp130 and an OSM 
receptor $\beta(O S M R ß)$ (11). Whereas LIF and OM both bind to type I receptor (12), the type II receptor is exclusively used by OM $(1,11,13,14)$. While in some cell types, receptors type I and II complexes are coexpressed and OM and LIF exert similar effects (15), numerous studies have shown that in several cell systems OM exhibits specific effects, which could not be recapitulated by LIF or IL-6, suggesting the predominant use of the type II receptor by OM $(13,16-20)$.

The binding of $\mathrm{OM}$ to its cognate receptors on cell surface triggers activation of janus-activated kinases (JAK1, JAK2 and TYK2) that promote phosphorylation of STATs (STAT1, STAT3, STAT5) (21). Phosphorylated STAT proteins form a homodimer or heretodimer and are translocated to the nucleus where they regulate gene expression by binding to their target sequences. Activation of JAK also leads to phosphorylation of the docking sites in the cytoplasmic region of the receptor for SHP-2 (3), which couples the activated receptors to the extracellular signal-regulated kinase (ERK) cascade, Ras/ Raf/MEK/ERK, leading to activation of expression of a different set of genes.

Although the interaction of OM with its receptors activates both STAT and ERK signaling cascades simultaneously, OM elicited biological responses show differential dependency to individual signaling pathway $(13,18,19)$. Our previous study conducted in breast cancer cells have showed that STAT3 activation plays a key role in the robust induction of fibronectin expression and induced cell migration by OM in MCF7 and T47D cells, whereas ERK activation was not required for those events (22). In contrast, activation of hepatic LDL receptor (LDLR) transcription by OM in liver cells absolutely depends on ERK activation and LIF is a weak inducer of LDLR expression compared to OM (23), implying that type II OMspecific receptor plays a major role in ERK activation and the subsequent stimulation of LDLR gene transcription.

Activation of STAT pathway has been linked to the induction of gene expression of several acute phase proteins by members of IL-6 family cytokines (24-26) and by OM (6) presumably through the type I receptor complex.

Thus, the unique and overlapping effects of OM with LIF and IL-6 through different utilizations of OM-exclusive type II receptor vs. the shared type I receptor raised an interesting question as whether different epitopes of $\mathrm{OM}$ were utilized to recognize type I vs. type II receptor chains, which could result in a preferential activation of one signaling pathway over the other.

In this study, we conducted site-directed mutagenesis on 13 amino acid residues that are part of the receptor-binding epitopes site 2 and site 3 . The effects of these mutations on OM-elicited signal transductions through ERK and STAT pathways were determined by bioassays. We used HepG2 cells as the assay system that naturally express both the type I and type II receptor complexes (11). The activation of transcription of LDLR by OM or its various mutants was measured as the readout for the regulation of lipid metabolism through ERK pathway and the induction of fibrinogen- $\beta$ (FGB) expression was used as the indicator of inflammatory response (24-27). We monitored the activation of MEK/ERK signaling cascade through phosphorylated ERK. Levels of phosphorylated STAT1 and STAT3 were examined to determine the activation of JAK/STAT signaling pathway by various OM mutants. Furthermore, based on the recent X-ray structures of LIF/gp130 (28), LIF/LIFR (29) complexes and OM (30), we performed homology modeling and molecular dynamics calculations to obtain a better understanding of the impact of our mutations on the ligand-receptor recognition mechanisms at site 2 and site 3 as well as on tertiary structural changes of OM. Together, these structure-activity relationship studies have revealed some new important structural features of $\mathrm{OM}$ and critical residues with regards to $\mathrm{OM}$ activation of the two different signaling pathways and their downstream target genes.

\section{Materials and methods}

Cells and reagents. The human hepatoma cell line HepG2 and COS7 were obtained from the American Type Culture Collection (ATCC) (Manassas, VA, USA). Cells were cultured in EMEM (Eagle's minimum essential medium) supplemented with $10 \%$ fetal bovine serum (FBS) (Summit Biotechnology, Fort Collins, CO, USA), $1 \mathrm{mmol} / \mathrm{l}$ streptomycin and $1 \mathrm{mmol} / \mathrm{l}$ penicillin. For Western blotting, antibodies directed to human OM, STAT1, STAT3 and ERK were obtained from Santa Cruz Biotechnology. Antibodies directed to phosphorylated ERK, STAT1 and STAT3 were obtained from Cell Signaling. Anti$ß$-actin was obtained from Chemicon (Temecula, CA).

Plasmid construction and mutagenesis. Plasmid pDOM9 contains a $664 \mathrm{bp}$ fragment of human OM cDNA that encodes the signal peptide and the mature protein amino acid residues 1-198 followed by a stop coden (31). This DNA fragment was released from the vector by $E c o \mathrm{R} 1$ digestion and subcloned into the plasmid pCIneo to yield the OM expression vector pCIneo-OM, which was used as the template to generate 13 alanine and 1 tyrosine replacement mutations by sitedirected mutagenesis using the QuickChange ${ }^{\mathrm{TM}}$ site-directed mutagenesis kit (Stratagene, San Diego, CA). OM mutants include S7A, K8A, Y10A, R11A, K19A, Q20A, D22A, L23A, D26A, G120A, G120Y, N123A, K163A and R175A. Primer sequences used in mutagenesis are listed in Table I. The correct mutation site in each plasmid was verified by dideoxy sequencing.

Transient plasmid transfection and detection of OM protein in conditioned cell culture medium. COS7 cells were seeded in 60-mm dishes at a density of $4 \times 10^{5}$ cells per dish overnight before the transfection. Transfection was performed by using FuGENE 6 Transfection Reagent (Roche Diagnostics, Indianapolis, IN, USA). Twenty-four hours later, the cultured medium was replaced with serum-free medium and cells were continuously cultured for another 2 days to reach $100 \%$ confluence. The serum-free cultured medium was collected as conditioned medium (CM). The CM was filtered through $0.2 \mu \mathrm{m}$ membrane. Western blotting was performed to detect $\mathrm{OM}$ protein in CM. Amounts of wt and various mutants in CM were quantified by human OSM DuoSet sandwich ELISA Development kit (R\&D Systems, Inc., Minneapolis, MN, USA) according to the manufacturer's protocol.

LDLR promoter luciferase reporter assay. HepG2 cells were cotransfected with plasmid pLDLR234Luc (23) and an empty 
Table I. Primer sequences.

\begin{tabular}{|c|c|c|}
\hline Mutant & Primers & Nucleotide sequence \\
\hline \multirow[t]{2}{*}{ S7A } & Wild-type & CGGCTATAGGCAGCTGCTCGAAAGAGTACCGCGTGCTCCTTG \\
\hline & OM-S7A-For & CGGCTATAGGCAGCTGCGCGAAAGAGTACCGCGTGCTCCTTG \\
\hline \multirow[t]{2}{*}{ K8A } & Wild-type & CTATAGGCAGCTGCTCGAAAGAGTACCGCGTGCTCCTTGG \\
\hline & OM-K8A-For & CTATAGGCAGCTGCTCGGCAGAGTACCGCGTGCTCCTTGG \\
\hline \multirow[t]{2}{*}{ Y10A } & Wild-type & CAGCTGCTCGAAAGAGTACCGCGTGCTCCTTGGCCAGCTCC \\
\hline & OM-Y10A-For & CAGCTGCTCGAAAGAGGCCCGCGTGCTCCTTGGCCAGCTCC \\
\hline \multirow[t]{2}{*}{ R11A } & Wild-type & CAGCTGCTCGAAAGAGTACCGCGTGCTCCTTGGCCAGCTC \\
\hline & OM-R11A-For & CAGCTGCTCGAAAGAGTACGCCGTGCTCCTTGGCCAGCTC \\
\hline \multirow[t]{2}{*}{ K19A } & Wild-type & СTCCTTGGCCAGCTCCAGAAGCAGACAGATCTCATGCAGG \\
\hline & OM-K19A-For & СTCCTTGGCCAGCTCCAGGCGCAGACAGATCTCATGCAGG \\
\hline \multirow[t]{2}{*}{ Q20A } & Wild-type & CTTGGCCAGCTCCAGAAGCAGACAGATCTCATGCAGGACAC \\
\hline & OM-Q20A-For & CTTGGCCAGCTCCAGAAGGCGACAGATCTCATGCAGGACAC \\
\hline \multirow[t]{2}{*}{$\mathrm{D} 22 \mathrm{~A}$} & Wild-type & CCAGCTCCAGAAGCAGACAGATCTCATGCAGGACACCAGC \\
\hline & OM-D22A-For & CCAGCTCCAGAAGCAGACAGCTCTCATGCAGGACACCAGC \\
\hline \multirow[t]{2}{*}{ L23A } & Wild-type & GCTCCAGAAGCAGACAGATCTCATGCAGGACACCAGCAGAC \\
\hline & OM-L23A-For & GCTCCAGAAGCAGACAGATGCCATGCAGGACACCAGCAGAC \\
\hline \multirow[t]{2}{*}{ D26A } & Wild-type & GCAGACAGATCTCATGCAGGACACCAGCAGACTCCTGGAC \\
\hline & OM-D26A-For & GCAGACAGATCTCATGCAGGCCACCAGCAGACTCCTGGAC \\
\hline \multirow[t]{2}{*}{ G120A } & Wild-type & CGAGGCCGAACATCCTCGGGCTCAGGAACAACATCTACTG \\
\hline & OM-G120A-For & CGAGGCCGAACATCCTCGCGCTCAGGAACAACATCTACTG \\
\hline \multirow[t]{2}{*}{ G120Y } & Wild-type & CGAGGCCGAACATCCTCGGGCTCAGGAACAACATCTACTG \\
\hline & OM-G120Y-For & CGAGGCCGAACATCCTCTACCTCAGGAACAACATCTACTG \\
\hline \multirow[t]{2}{*}{ N123A } & Wild-type & GAACATCCTCGGGCTCAGGAACAACATCTACTGCATGGCCC \\
\hline & OM-N123A-For & GAACATCCTCGGGCTCAGGGCCAACATCTACTGCATGGCCC \\
\hline \multirow[t]{2}{*}{ K163A } & Wild-type & CTCGGATGCTTTTCAGCGCAAGCTGGAGGGCTGCAGGTTC \\
\hline & OM-K163A-For & CTCGGATGCTTTTCAGCGCGCGCTGGAGGGCTGCAGGTTC \\
\hline \multirow[t]{2}{*}{$\mathrm{R} 175 \mathrm{~A}$} & Wild-type & GGTTCCTGCATGGCTACCATCGCTTCATGCACTCAGTGGG \\
\hline & OM-R175A-For & GGTTCCTGCATGGCTACCATGCCTTCATGCACTCAGTGGG \\
\hline
\end{tabular}

vector pcDNA3.1 containing a neomycin resistant gene in a DNA ratio of 50:1 using Fugen 6 transfection reagent. Stable clones were selected by G418 (Invitrogen) at the concentration of $800 \mu \mathrm{g} / \mathrm{ml}$. Clone B11 having a high level of luciferase activity was used to examine the transcriptional effects of the wt and mutant OM on LDLR gene. B11 cells were seeded in 96-well plates at a density of $5 \times 10^{4}$ cells/well. Twenty-four hours later, the cells were treated for $4 \mathrm{~h}$ with human recombinant (hr) OM or various CMs collected from transfected COS7 cells. Luciferase activities were measured using the Promega Luciferase assay system (Promega, Madison, WI, USA). Triplicate wells were assayed for each condition.

Detection of activated ERK and activated STAT3 and STAT1 by Western blot analysis. HepG2 cells seeded in 12-well plate were incubated in $0.5 \%$ FBS for $4 \mathrm{~h}$. Either hr-OM or the
OM-containing $\mathrm{CM}$ at indicated concentrations was added to the cells for 15 min prior to cell lysis. This treatment time was selected based upon our previous studies conducted in HepG2 cells that showed the highest levels of phosphorylated ERK and STAT after a 15-20 min treatment of OM $(22,23)$. Cell lysis buffer (50 mM Tris, $\mathrm{pH} 8.0,1 \%$ Nonidet P40, $0.25 \%$ sodium deoxycholate and $150 \mathrm{mM} \mathrm{NaCl}$ ) was supplemented with protease inhibitor cocktail (1:100 dilution, Roche Diagnostics GmbH, UK) and phosphotase inhibitor cocktail (1:100 dilution, Sigma). Protein concentration in cell lysate was determined by BCA protein assay. Protein $(50 \mu \mathrm{g})$ was separated onto 4-20\% gradient sodium dodecyl sulfatepolyacrylamide gel (Cambrex Bioscience Inc, Rockland, ME) and were transferred onto a nitrocellulose membrane. After blocking with $1 \%$ BSA in TBST $(10 \mathrm{mM}$ Tris- $\mathrm{HCl} \mathrm{pH} 7.4$, $150 \mathrm{mM} \mathrm{NaCl}$ and $0.1 \%$ Tween-20) membranes were immunoblotted with primary antibodies. The bound primary 
Table II. Equivalence of nomenclature of residue atom names between this study and standard name from Protein Data Bank (PDB).

\begin{tabular}{|c|c|c|}
\hline Residue & $\begin{array}{l}\text { Atom notation } \\
\text { (This study) }\end{array}$ & $\begin{array}{l}\text { Atom notation } \\
\text { (PDB) }\end{array}$ \\
\hline \multirow[t]{2}{*}{ Asn } & 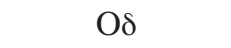 & OD1 \\
\hline & 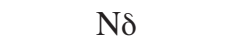 & ND2 \\
\hline Asp & Oঠ & OD1, OD2 \\
\hline \multirow[t]{2}{*}{ Gln } & $\mathrm{O} \varepsilon$ & OE1 \\
\hline & $\mathrm{N} \varepsilon$ & NE2 \\
\hline Ser & $\mathrm{O} \gamma$ & OG \\
\hline Thr & $\mathrm{O} \gamma$ & OG1 \\
\hline
\end{tabular}

antibodies were probed with horseradish peroxidaseconjugated secondary antibodies and the signals were detected using an ECL-plus western detection system (Amersham, Buckinghamshire, UK). Membranes were reprobed with anti-actin antibody to correct for differences in protein loading.

Quantitative real-time RT-PCR analysis. Expression levels of LDLR and FGB mRNA were examined by TaqMan real-time RT-PCR. Cells were treated with hr-OM or CM for various lengths of time at different concentrations. Total RNA was extracted by the Ultraspec ${ }^{\mathrm{TM}}$ total RNA isolation reagent (Biotecx laboratories INC, Houston, TX, USA). The reverse transcription was performed with $2 \mu \mathrm{g}$ of total RNA, random primers and MuLV reverse transcriptase (Applied Biosystems, Foster City, CA) at $37^{\circ} \mathrm{C}$ for $2 \mathrm{~h}$ in a volume of $25 \mu 1$. The cDNA volume was diluted to 250 and $2 \mu 1$ was mixed with TaqMan real-time primers and probes for amplification using ABI Prism 7900-HT Sequence Detection System (Applied Biosystems). A set of predesigned primers and a probe for each testing gene were obtained from Applied Biosystems. assay IDs are as follows: LDLR, Hs00181192_m1; FGB, Hs00170586_m1 and GAPDH, Hs99999905_m1. The relative mRNA expression level of individual gene for each sample was normalized for input RNA against GAPDH expression. For data analysis, threshold cycle $\left(\mathrm{C}_{\mathrm{T}}\right)$ values for each reaction were determined using TaqMan SDS analysis software. Triplicate assays were done for each RNA sample.

Statistical analysis. For the functional characterization of mutant groups, two-tailed Student's t-test was used to compare the mean values of fold increase in LDLR promoter between group 1 and group 2, or between wt and each mutant.

Molecular modeling. The experimental structures of OM/ gp130/LIFR and OM/gp130/OSMR ternary complexes are so far lacking. Here homology models for LIFR and OSMR were produced by using the mouse LIFR structure [inside the LIF/mLIFR complex (29)], which shares 64 and 30\% sequence identity (SI) with human LIFR and OSMR, respectively. Models of the complexes were constructed by fitting the X-ray structure of LIF in LIF/gp130 (PDB entry: 1PVH) (28) onto that of LIF in LIF/mLIFR (PDB entry: 2Q7N) (29). The resulting $\mathrm{LIF} / \mathrm{gp} 130 / \mathrm{mLIFR}$ complex was transformed into the human OM/gp130/LIFR and OM/gp130/OSMR ternary complexes by homology modeling. Although the SI between LIF and OM is low (20\%), they are structurally similar (30). Thus, we used LIF structure inside the complex and the OM structure in solution (PDB entry: 1EVS) (30) as templates to construct $\mathrm{OM}$ inside the two complexes. OM and LIF were structurally aligned by means of STAMP (32). The procedure was carried out with the Modeller 9v1 program (33). Then, the two models with the top Modeller-score were refined using the Haddock 2.0 program (34). G20A, G120A, N123A and K163A OM mutant structures were obtained by using the Swiss-Pdb Viewer program (35). Wild-type and mutant proteins were finally relaxed by short molecular dynamics (MD) runs. Equivalent nomenclature of residue atom names between this study and standard names from Protein Data Bank (PDB) is listed in Table II.

\section{Results}

Oncostatin $M$ induces LDLR, FGB mRNA expression and ERK, STAT1 and STAT3 phosphorylation dose-dependently in HepG2 cells. HepG2 cells were treated with increasing concentrations of hr-OM (0.5-80 ng/ml) for $2 \mathrm{~h}$. Expression levels of LDLR and FGB were examined by quantitative real-time RT-PCR (Fig. 1A). Hr-OM at the concentration of $0.5 \mathrm{ng} / \mathrm{ml}$ induced a 2-fold elevation of LDLR mRNA level and at $2 \mathrm{ng} / \mathrm{ml} \mathrm{hr}-\mathrm{OM}$ increased LDLR mRNA level by 2.8-fold. The LDLR mRNA expression was slightly increased to a maximum of 3-fold at higher hr-OM concentrations.

The induction of FGB mRNA expression by hr-OM followed a similar dose-dependent pattern. It was increased to 1.6 -fold of control at a concentration of $0.5 \mathrm{ng} / \mathrm{ml}$, to 2.6-fold of control at $2 \mathrm{ng} / \mathrm{ml}$ and $\mathrm{hr}-\mathrm{OM}$ reached its maximal induction of 4.1 -fold at $20 \mathrm{ng} / \mathrm{ml}$. To correlate changes in LDLR and FGB transcription with activations of ERK and STAT signaling pathways, we examined dose-dependent effects of hr-OM on ERK, STAT3 and STAT1 phosphorylation (Fig. 1B). At resting stage, phosphorylated ERK, STAT3 and STAT1 were barely detectable in HepG2 cells, whereas they were clearly seen after a $15-\mathrm{min}$ incubation with $0.5 \mathrm{ng} / \mathrm{ml}$ hr-OM. Levels of phosphorylated ERK, STAT3 and STAT1 reached maximums in cells treated with $2-4 \mathrm{ng} / \mathrm{ml} \mathrm{hr-OM}$ and stayed at the plateau with higher hr-OM concentrations. This dose-dependent induction of ERK and STAT phosphorylations showed a good correlation with induction of LDLR and FGB gene expression by OM. These experiments together defined a concentration range that is important for subsequent studies to compare different potencies of wt and mutant OM in these bioassays.

Production and evaluation of bioactive $O M$ and mutants in conditioned cell culture medium of COS7 cells after transient transfection. We chose COS7 cells as the mammalian expression system to rapidly produce bioactive $\mathrm{OM}$ and its mutants. COS7 cells were transiently transfected with plasmid pCIneo-OM that encodes OM signal peptide and the mature protein (aa 1-198) or the control empty vector pCIneo. Western blotting with specific anti-OM antibody showed a band of 
A

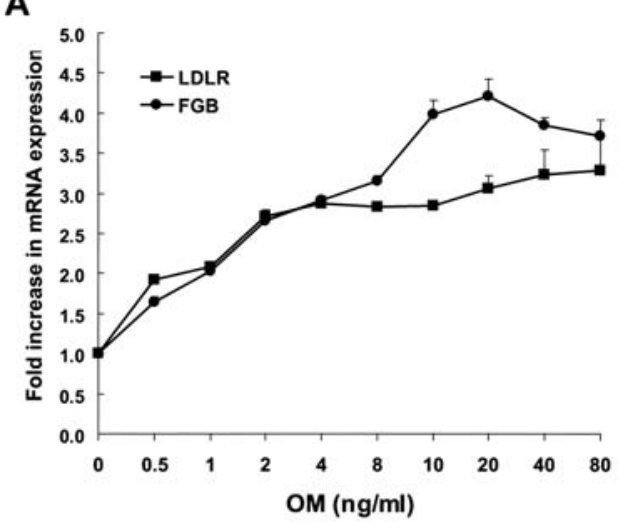

B

$\mathrm{OM}(\mathrm{ng} / \mathrm{ml}): \begin{array}{lllllll}0 & 0.5 & 1 & 2 & 4 & 10 & 20\end{array}$

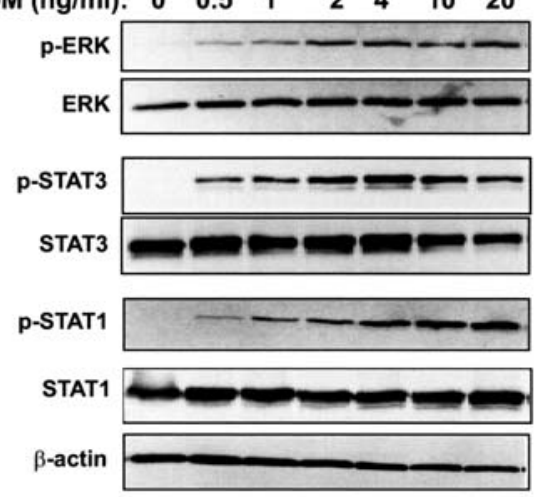

Figure 1. Dose-dependent effects of OM on LDLR and FGB mRNA expression and on phosphorylations of ERK and STAT signaling molecules (A) HepG2 cells were treated with human recombinant $\mathrm{OM}$ at indicated concentrations for $2 \mathrm{~h}$. Total RNA was isolated and mRNA levels of LDLR, FGB and GAPDH were analyzed by real-time quantitative RT-PCR. After normalization with GAPDH mRNA levels, the abundance of LDLR or FGB mRNA in untreated cells was defined as 1 and the amounts of LDLR or FGB mRNA from OM-treated cells were plotted relative to that value. The figure shown is representative of 3 independent experiments in which each sample was assayed in triplicates. (B) HepG 2 cells in $0.5 \%$ FBS EMEM were stimulated with different doses of OM for $15 \mathrm{~min}$ and total cell lysate was prepared. Western blot analysis was carried out using antibodies specific for phospho-ERK, ERK, phospho-STAT1, STAT1, phospho-STAT3, STAT3 and ß-actin.

approximate molecular mass of $28 \mathrm{kDa}$ in the culture medium of pCIneo-OM-transfected cells, which was absent in the culture medium of pCIneo transfection. The abundance of OM in culture medium was further quantified by ELISA using hr-OM produced from E. coli as the standard. The ELISA results showed similar amounts of wt and mutated OM in conditioned medium (CM).

The time-dependent effects of induction of LDLR and FGB mRNA expression by CM of pCIneo-OM transfected cells were examined side by side with hr-OM. While control $\mathrm{CM}$ of empty vector pCIneo-transfected cells had no effects on LDLR or FGB gene expression, CM of pCIneo-OM and hr-OM induced rapid elevations in LDLR mRNA levels. Increases were detected as early as $30 \mathrm{~min}$ of $\mathrm{OM}$ addition, reached maximal levels by $1 \mathrm{~h}$ and slowly declined (Fig. 2A, upper panel). In contrast to LDLR mRNA, levels of FGB mRNA rose continuously with treatment times. These results indicate that OM in CM activates LDLR and FGB transcription with kinetics identical to the hr-OM.
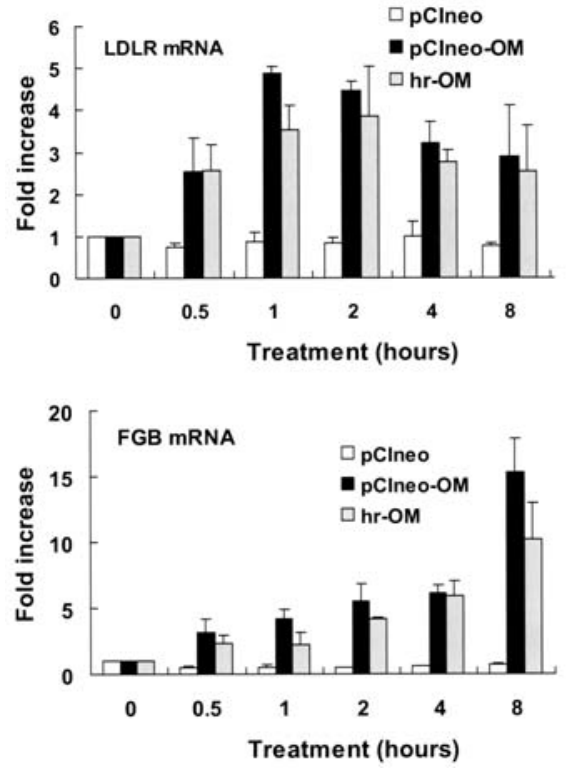

Figure 2. Analysis of bioactivity of OM from conditioned medium (CM) of COS7 cells. HepG2 cells were treated with $2 \mu 1$ of CM of pCIneo-OM, $2 \mu 1$ of $\mathrm{CM}$ of pCIneo control vector, or with human recombinant $\mathrm{OM}$ (hr-OM) $(50 \mathrm{ng} / \mathrm{ml})$ for the indicated time periods to determine the time-dependent effects of OM on LDLR and FGB gene expression.

Mutant plasmid construction and expression in COS7 cells. In a previous mutagenic study conducted in BAF cells, mutations of several residues in site 2 and site 3 of OM receptor recognition epitopes differentially affected OM proliferative activities mediated through the type I or type II receptors (30). However, how these mutations affect OM-elicited signal transductions was not directly examined. Hence, we selected 12 mutation sites from that study to remake 12 alanine replacement mutants and one tyrosine replacement by utilizing site-directed mutagenesis. These mutations include 2 mutations (S7A and K8A) on the N-terminus, 7 mutations on helix A (Y10A, R11A, K19A, Q20A, D22A, L23A, D26A), 3 mutants on helix C (G120A, G120Y, N123A) and one mutant (K163A) on helix D. In addition, we made one new mutant R175A on helix D that was not examined in the previous study reported by Deller et al (30). Locations of mutant residues are shown in Fig. 3A. Mutant plasmids were transfected into COS7 cells and conditioned media were examined for OM expression by Western blotting. The $28 \mathrm{kDa}$ band of OM was detected in all CMs but this band was not shown in mock-transfected control cells (Fig. 3B).

Different effects of mutations on OM-stimulated LDLR transcription. We established a HepG2-derived cell line (B11) that stably expressed LDLR promoter-luciferase reporter (pLDLR234Luc). This cell line was used to test the effects of mutations on OM-mediated LDLR gene transcription. B11 cells were treated for $4 \mathrm{~h}$ with different $\mathrm{CMs}$ at the concentrations equivalent to 2 or $50 \mathrm{ng} / \mathrm{ml}$ of $\mathrm{OM}$ (Fig. 3C). Analysis of luciferase activities in treated cells revealed that these 13 mutants fell into 3 different categories. The first class of mutant behaved like the wt OM. They increased luciferase activity 2.3 -fold at the low $\mathrm{OM}$ concentration of $2 \mathrm{ng} / \mathrm{ml}$. This group of mutants is site 2 mutants including two mutants of $\mathrm{N}$-terminus (S7A and K8A) and 6 mutants of helix A. The 

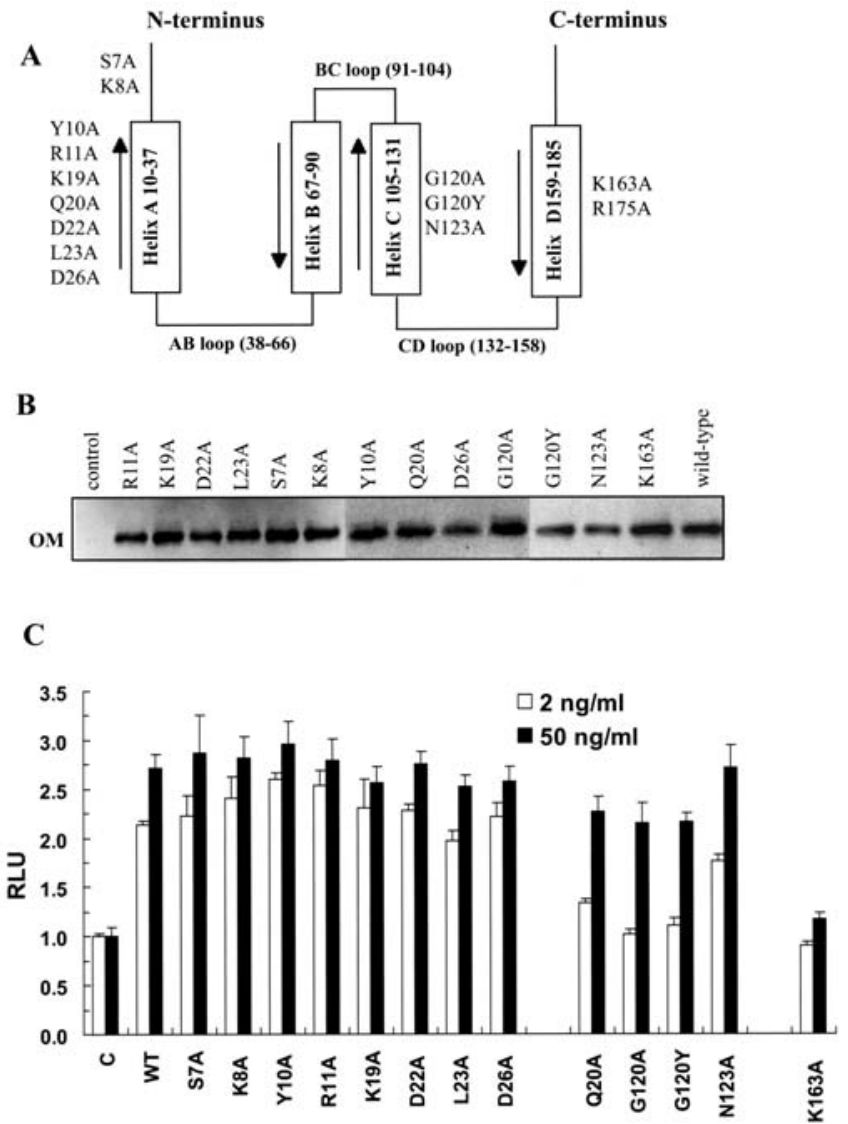

Figure 3. Expression of wt and mutant OM. (A) Schematic drawing of the $4 \alpha$-helices (A, B, C, D) and the position of mutation sites. (B) Wild-type or mutant plasmid was transfected into COS7 cells. After 3 days of transfection, $\mathrm{CM}$ was collected, filtered and subjected to Western blotting with anti-OM antibody. (C) Cells of HepG2 clone B11 were treated with wt or mutant OM at concentrations of 2 and $50 \mathrm{ng} / \mathrm{ml}$ for $4 \mathrm{~h}$. Cells were lysed and luciferase activity was measured. The data shown are representative of 4 independent transfection assays.

second class of mutants partially lost the OM effect. This group includes four site 2 mutants (Q20A, G120A, G120Y and $\mathrm{N} 123$ ). At $2 \mathrm{ng} / \mathrm{ml}$, they increased LDLR promoter activity to an average of 1.3-fold, which was statistically lower than the wt and the group 1 mutant $(\mathrm{p}<0.001)$. At a higher OM concentration of $50 \mathrm{ng} / \mathrm{ml}$, this group induced a 2.3-fold increase in luciferase activity which was still lower than the wt and group 1 (2.3-fold vs. 2.7-fold, $\mathrm{p}<0.05)$. The mutation of K163A on site 3 produced a loss of function mutant that could not activate LDLR promoter even at the high concentration of $50 \mathrm{ng} / \mathrm{ml}$. Together, the rapid LDLR reporter assays provided initial clues of the mutational effects.

Analysis of effects of various mutations on ERK and STAT signal transductions. Next, we performed detailed analyses of the impact of various mutations on OM-elicited signal transductions.

To examine the loss of function of K163A, we compared the dose-dependent effects of wt and K163A up to 100 -fold concentration range $(0.5-50 \mathrm{ng} / \mathrm{ml})$ (Fig. $4 \mathrm{~A})$. Quantitative real-time RT-PCR assays showed that $0.5 \mathrm{ng} / \mathrm{ml}$ wt OM increased LDLR expression 2.7-fold and FGB 2.5-fold over control after 2-h stimulation. At $50 \mathrm{ng} / \mathrm{ml}$ of OM, levels of LDLR and FBG mRNAs were further increased to 6.8- and
A
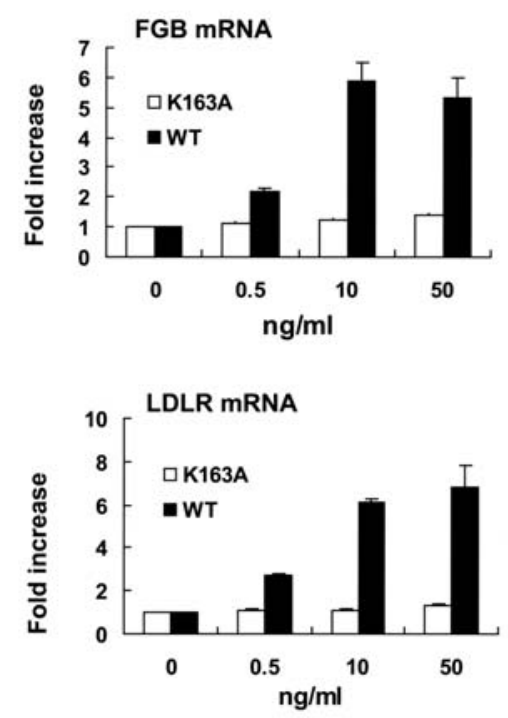

B

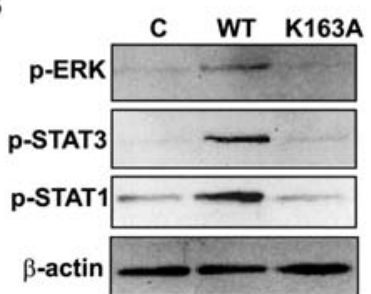

Figure 4. Mutation of Lys163 abrogates OM-mediated signaling. (A) Cells were treated with wt OM or K163A for $2 \mathrm{~h}$ at the indicated doses. Relative mRNA levels of LDLR and FGB in control and OM-treated cells were assessed by real-time quantitative RT-PCR. (B) Cells were treated with $2 \mathrm{ng} / \mathrm{ml}$ of wt or $50 \mathrm{ng} / \mathrm{ml}$ of K163A for $15 \mathrm{~min}$ prior to cell lysis for Western blotting. The picture shown is a representative of 2 separate experiments with similar results.

5.4-fold of control, respectively. These dose-dependent effects were not observed at all in cells treated with K163A. This was correlated with a lack of induction of phosphorylated ERK as well as phosphorylated STAT3 and STAT1 (Fig. 4B). Interestingly, in contrast to Lys163, the mutation of Arg175 to Ala on Helix D did not alter OM activity. R175A mutant induced the phosphorylation of both ERK and STATs and stimulated LDLR and FGB gene expression dose-dependently to the same extents as the wt OM (Fig. 5). Other wt-like mutants showed similar induction of ERK and STAT phosphorylations and activation of LDLR and FGB transcription in these assays (data not shown).

Site 2 Gly120 mutations impaired both ERK and STAT signaling pathways. Fig. 6A shows that mutations of Gly120 to G120A and to G120Y substantially reduced both OM stimulatory activities on LDLR and FGB gene expression. Mutants at $1 \mathrm{ng} / \mathrm{ml}$ did not show any induction, at $10 \mathrm{ng} / \mathrm{ml}$ concentrations, mutants only increased LDLR and FGB mRNA expression to levels similar to the increase caused by $1 \mathrm{ng} / \mathrm{ml}$ wt OM, suggesting a 10 -fold reduction in receptor binding affinity. Fig. 6B confirms that these mutants were weak inducers in stimulating ERK and STAT phosphorylation. 

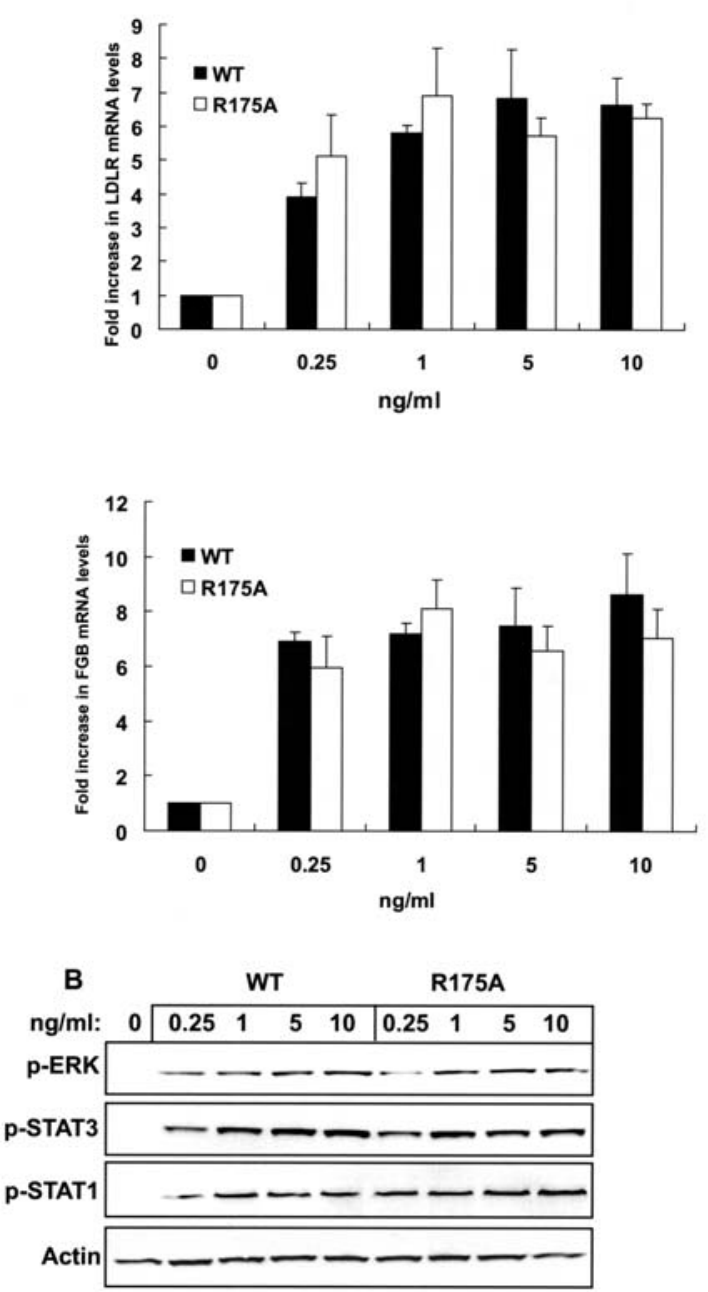

Figure 5. R175A mutant fully preserves OM functions. (A) Dose-dependent effects of R175A on induction of LDLR and FGB gene expression were compared with the wt OM. (B) Cells were treated with R175A or wt OM at the indicated concentrations for $15 \mathrm{~min}$. Western blot analysis was performed to detect the activation of ERK and STAT1/3 in treated cells.

Q20A and N123A differentially affected ERK and STAT signaling pathways. Fig. 7A compares the dose-dependent effects of Q20A and N123A with wt OM on LDLR and FGB mRNA expression levels in HepG2 cells. Both Q20A and N123A showed lesser activity in FGB induction than LDLR induction. At $2 \mathrm{ng} / \mathrm{ml}$, effects of N123A on LDLR and FGB inductions were 81 and $55 \%$ of the wt respectively. At $10 \mathrm{ng} / \mathrm{ml}, \mathrm{N} 123 \mathrm{~A}$ reached $100 \%$ activity of the wt on LDLR induction but it only showed $70 \%$ activity of the wt on FGB induction. Similarly, Q20A mutation had a less impaired activity on LDLR induction than that in FGB induction.

Next, we examined the dose-dependent effects of Q20A and N123 on ERK and STAT phosphorylation. Fig. 7B shows that signal intensities of phosphorylated STAT1 and STST3 of Q20A and N123A were lower than the wt. Particularly, at the $0.5 \mathrm{ng} / \mathrm{ml}$ concentration, STAT1 phosphorylation was not observed. In contrast, the induction of ERK phosphorylation by OM was not impaired by these mutations (Fig. 7C). These data suggested that Q20A and N123A mutations might preferentially affect STAT signaling pathway without compromising the ERK signaling pathway.
A
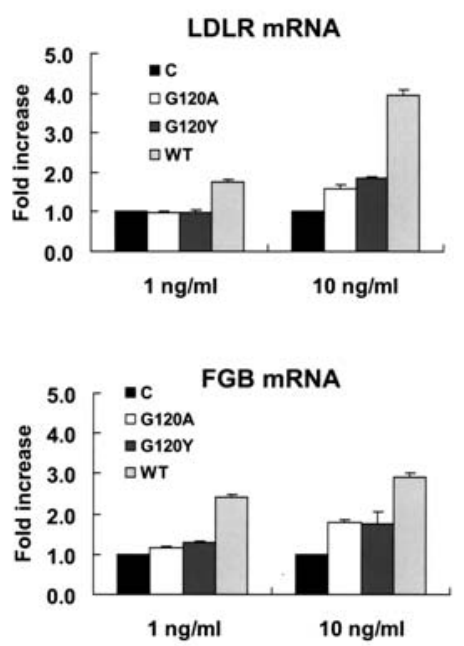

B

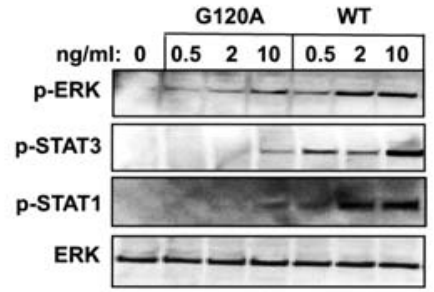

Figure 6. Gly120 mutation affected OM signaling through both ERK and STAT pathways. (A) HepG2 cells were treated with wt OM, G120A, or $\mathrm{G} 120 \mathrm{Y}$ at 1 and $10 \mathrm{ng} / \mathrm{ml}$ doses. After a 2-h treatment, total RNA was isolated for real-time RT-PCR analysis of LDLR and FGB mRNA expression. (B) Cells were treated with different doses of wt, G120A, or G120Y for $15 \mathrm{~min}$. Whole cell lysis were prepared and Western blot analysis was carried out as described in Fig. 1B.

Molecular modeling. The effect of OM mutations on the signaling pathways may be caused by affecting the interaction of OM with gp130, LIFR and/or OSMR. To investigate the structural role of the residues involved in the mutations as well as the effect of the mutations performed herein, we have constructed structural models of wt and mutated OM/gp130/ LIFR and OM/gp130/OSMR complexes using computational methods (see Methods). Although these models are certainly not as reliable as experimentally derived structures, they do provide precious qualitative insights on protein complexes (36).

Structure of wt ternary complexes. We first summarize the salient features of the two complexes obtained by homology modeling and molecular dynamics simulations. OM binds LIFR at the Ig-like domain, D3, and at the domain D4 belonging to the second CBM at lower extent (Figs. 8 and 9A). OM binds OSMR at the Ig-like domain, D2, and, at lower extent at, the domain D3 (Figs. 8 and 9B). Finally, OM binds gp130 at the CBM, namely the domain D2 and, at lower extent, D3 (Figs. 8 and 9C).

Next, we focus on the binding sites 3 in both ternary complexes. As demonstrated in the previous mutagenesis study, Phe160 and Lys163 are key residues of OM for LIFR binding (30).

In our model, Phe160 important role is due to the formation of hydrophobic interactions with its cognate protein. Indeed, 
A

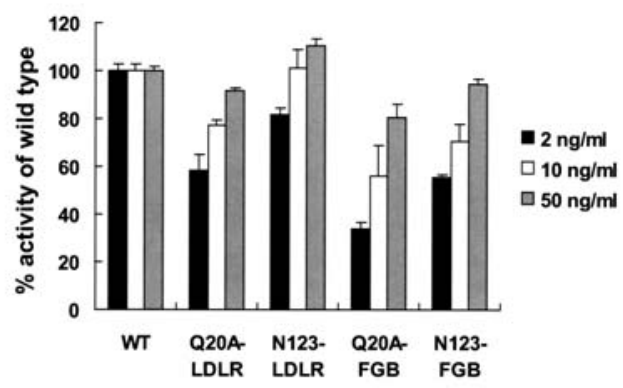

B

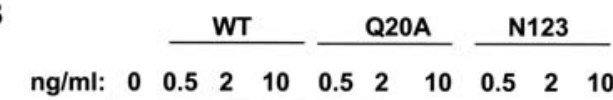

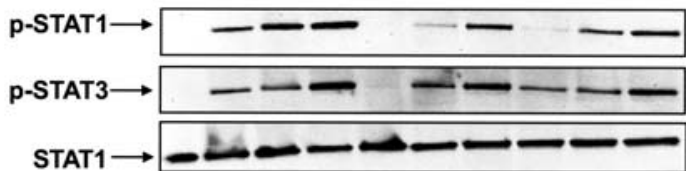

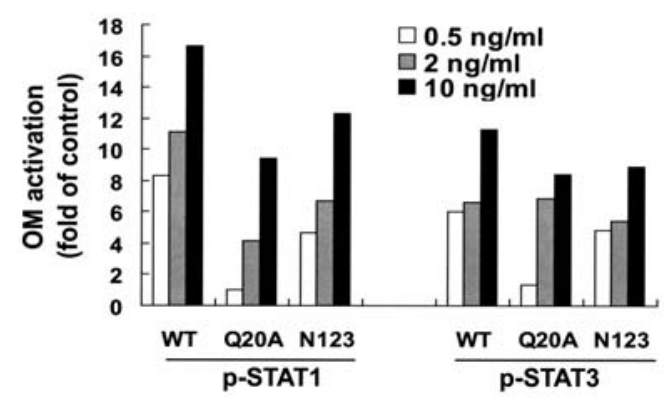

C
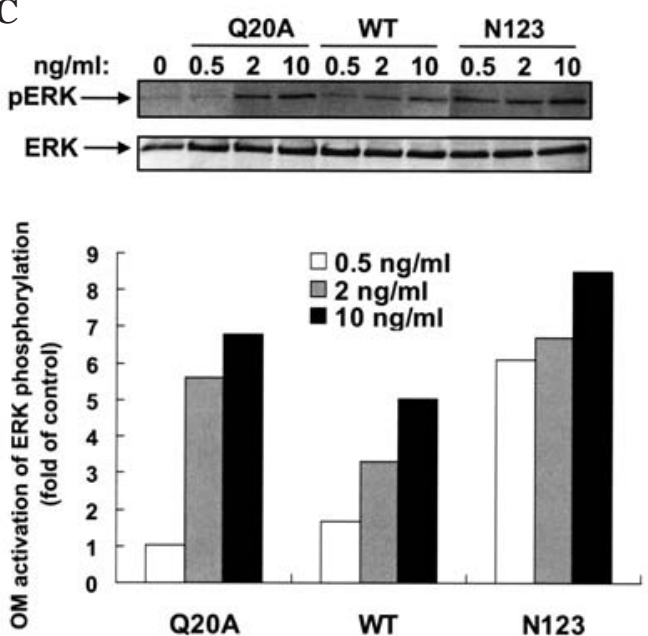

Figure 7. Mutations of Gln20 and Asn123 specifically diminished OM ability to activate STAT1 and STAT3 without compromising ERK activation. (A) HepG2 cells were treated with wt OM, Q20A and N123A at the indicated concentrations for $2 \mathrm{~h}$. Real-time RT-PCR was performed. To illustrate the mutational effects on OM activity in LDLR vs. FGB gene expression, at each concentration, the fold increase of LDLR or FGB mRNA expression over untreated control by wt OM was expressed as $100 \%$ and the fold induction by each mutant was plotted relative to that value. (B and C) Dose-dependent activations of STAT1, STAT3 and ERK by wt, Q20A and N123A were examined. The signal intensities were quantified using Kodak Imaging station. The data shown are representative of two separate experiments with similar results.

it is part of a hydrophobic patch along with Leu45 and Leu164. This patch interacts with residues Val272, Ile278 and Gly280 of LIFR domain D3 (Fig. 9A). The role of Lys163

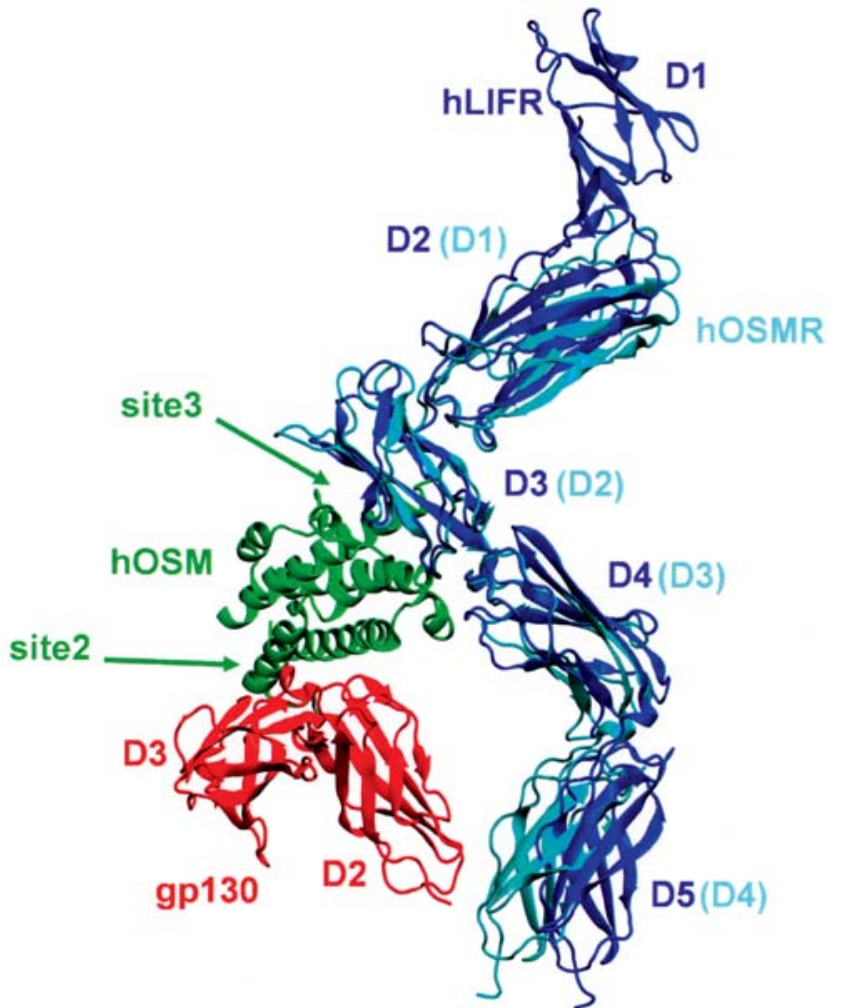

Figure 8. Graphic representation of the two superimposed models of the tertiary complexes of human OM with gp130, with human LIFR or with human OSMR. OM is reported in green, gp130 (D2-D3) in red, LIFR (D1-D5) in blue and OSMR (D1-D4) in cyan.

for LIFR binding is instead established by the formation of an extended hydrogen bond network with $\mathrm{O} \gamma$ of Ser266, Os of Asn269 and Gly267 carbonyl of LIFR. The first two form additional H-bonds with OM: Ser266 with $\mathrm{O} \varepsilon$ of Gln38 and Ile37 carbonyl, whilst No of Asn269 with Gln38 and Gly39 backbone carbonyls. Several other residues contribute to complex stability by forming H-bonding interactions as shown in Fig. 9A.

Previously, Phe160 and Lys163 were indicated also the most important OM residues for OSMR binding at site 3 (30). Indeed, in our model Phe160 forms a similar hydrophobic patch with similar interactions as in OM/gp130/LIFR. However, the hydrogen bond network formed by Lys163 is slightly different because Lys182 replaces Ser266 (Fig. 9B). In fact, Lys 163 only forms two H-bonds (with Gly 183 carbonyl and OS of Asn185) instead of three. The replacement of Ser266 with a lysine also causes the loss of the H-bonds formed by this residue in OM/gp130/LIFR (Fig. 9AB). The complex is further stabilized by salt bridges and additional H-bonds as shown in Fig. 9B.

Finally, we turn our attention to the OM/gp130 interface, located at $\mathrm{OM}$ site 2 and common in both complexes (Fig. 10C). Gln16, Gln20, Gly120, Asn124 are key residues of OM for gp130 binding (30). In addition, our study points out also to an important role of Asn123 in the complex formation.

Gln16, Asn124, Asn123 H-bonds with the cognate protein:

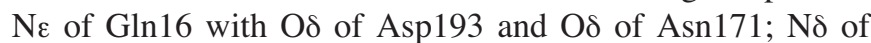
Asn124 with Phe169 carbonyl; No of Asn123 with O $\gamma$ of 


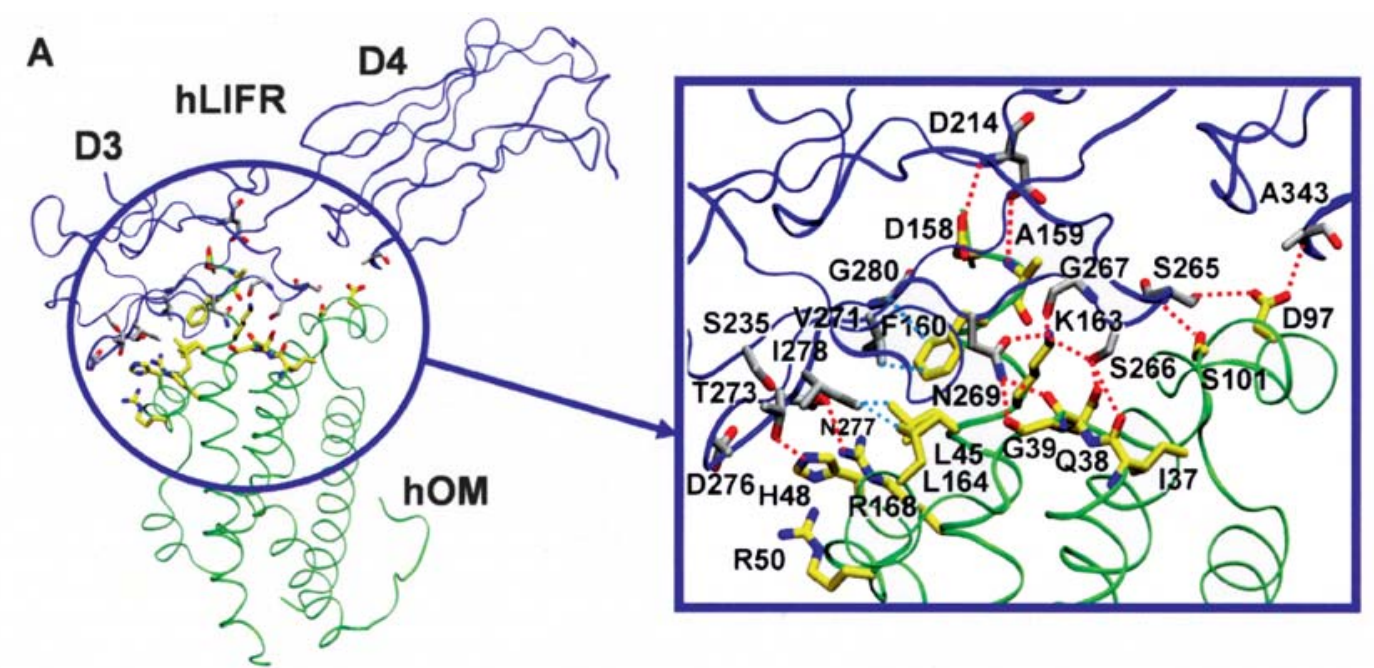

B
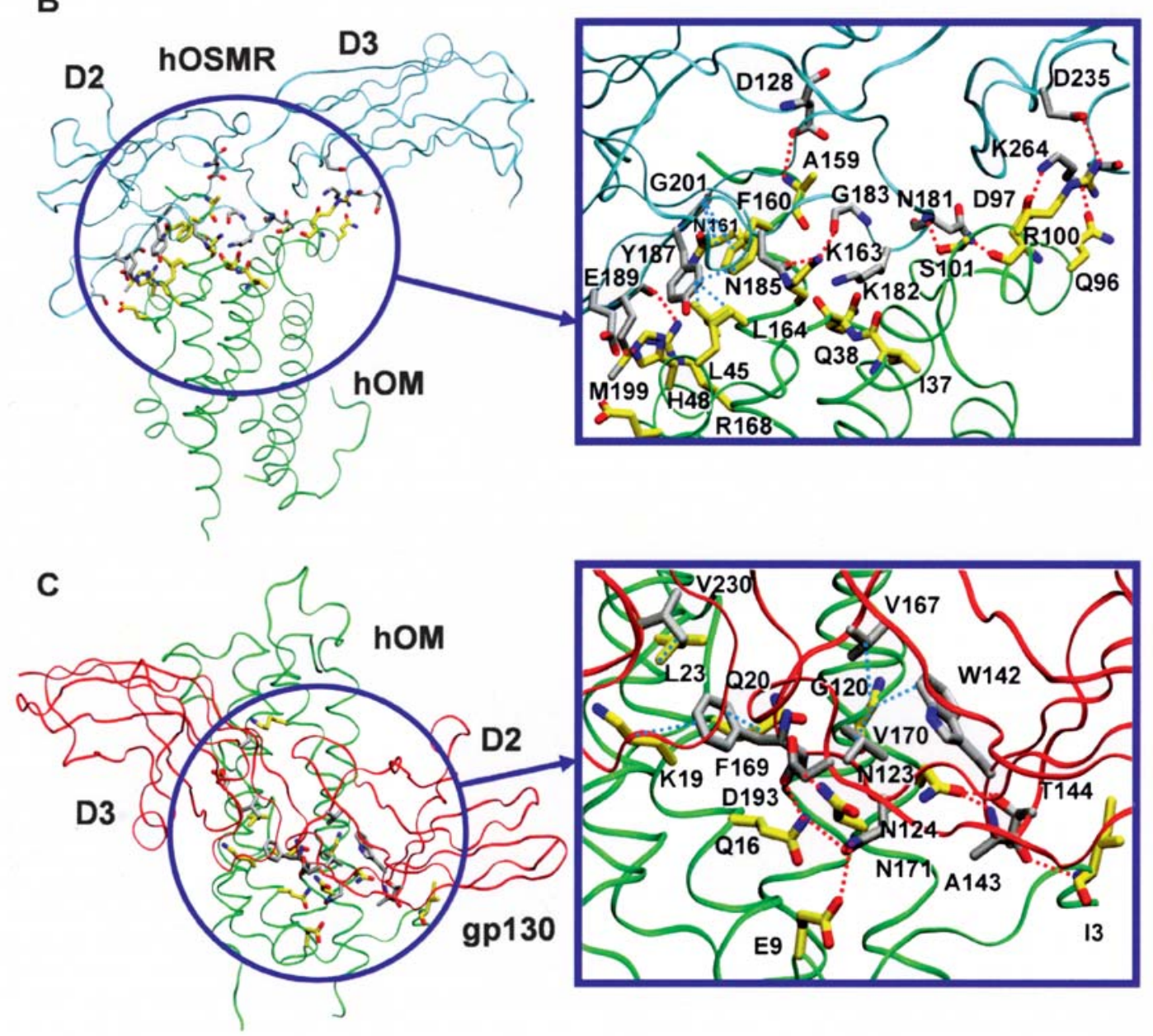

Figure 9. Graphic representation of the interactions between human OM and LIFR at site 3 (A), OM and OSMR at site 3 (B) and OM and gp130 at site 2 (C). OM is reported as green ribbons, LIFR as blue ribbons, OSMR as cyan ribbons and gp130 as red ribbons. Residues forming interactions are reported as sticks and colored in yellow if they belong to OM or in gray if they belong to the receptors. H-bond networks are reported by red dashed lines.

Thr144 and the backbone nitrogen of Ala143 (Fig. 9C). Gly120 interacts with Val167, Trp142 and Val170 of gp130. Gln20 does not form specific interactions with gp130. Instead the side chain of Gln20 can form an H-bond with $\mathrm{N} \delta$ of Asn124. Finally, additional H-bonds stabilize the OM/gp130 complex as shown in Fig. 9C.
Structure of ternary complexes mutated in this study K163A. This mutation at site 3 causes an obvious disruption of interactions with both LIFR and OSMR along with a partial unfolding at the N-terminus domain of helix F (Fig. 10C) as shown by MD simulations. As a result, the binding pocket at site 3 reduces its volume of $\sim 60 \%$ with respect to the wt 

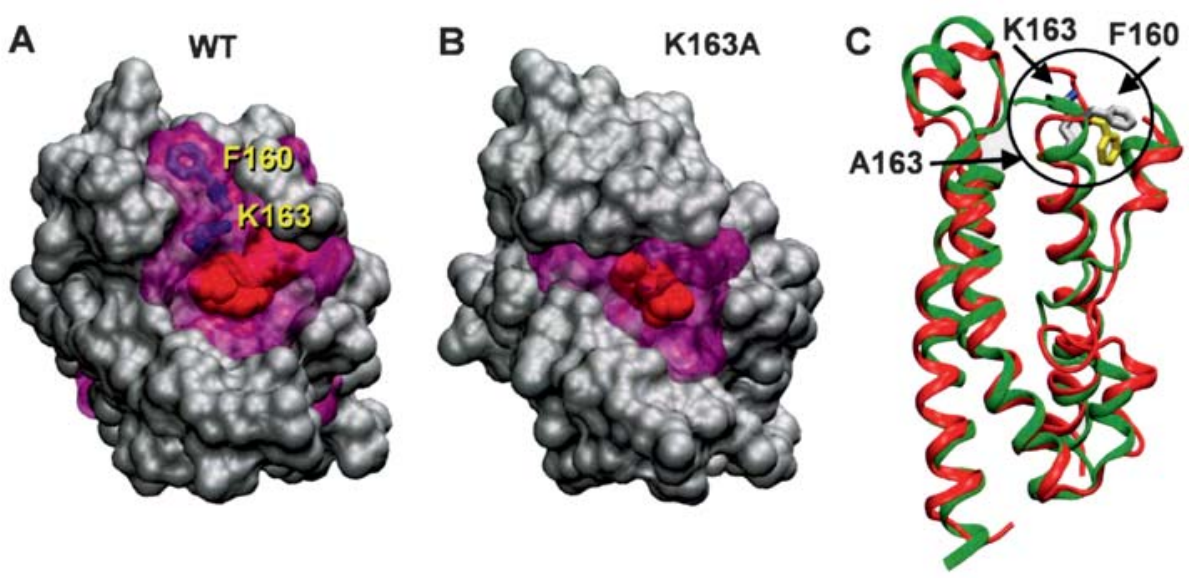

Figure 10. Models of solvent accessible surface area of wt human OM (A) vs. mutant K163A (B) at site 3. Residues forming the cavity are represented as purple surfaces and Phe160 and Lys163 are represented as blue sticks. Cavity volumes are represented by red balls. (C) Superimposition of wt OM (green ribbons) and mutant K163A (blue ribbons) after 6 ns of MD. Phe160 and Lys(Ala)163 are represented as sticks: wt residues are colored in gray, K163A residues are colored in yellow. The circle frames the region of partial unfolding of helix F.

(Fig. 10A and B). At the same time, Phe160 gets buried and its solvent accessible surface area (SASA) changes from $88 \AA^{2}$ to $8 \AA^{2}$ on average (Fig. 10C). These findings can explain why mutant $\mathrm{K} 163 \mathrm{~A}$ does not bind either type I or type II receptors. All the other mutants are located in site 2 .

G120A. Because Gly120 is tightly inserted in a hydrophobic pocket of gp130, the insertion of a bulkier residue such as Ala affects the binding because of alanine steric hindrance. Even larger effect can be expected for G120Y, although in this case the model was not constructed. We therefore suggest that mutants G120A and G120Y show a reduction of binding activity for both type I and type II receptors mostly because of the lowering of affinity between gp130 and OM.

$N 123 A$. In our models, the replacement of Asn123 with alanine implies the loss of an H-bond with Thr144 and Ala143. However, alanine methyl group forms hydrophobic interactions with several apolar residues nearby belonging to gp130 (Fig. 9C), which are expected to stabilize the complex. In addition, this mutation causes a rearrangement of OM residues Ile 37 and Gln38 at site 3 . This causes a differential behavior in the two complexes. In LIFR, the H-bonds formed with Ser266, present in the wt, are disrupted. In contrast, in OSMR, Lys186 (equivalent to Ser266 in LIFR) does not interact with $\mathrm{OM}$ residues Ile37 and Gln38. Therefore, we predict that the affinity for LIFR is decreased, whilst that of OSMR is basically the same. This is consistent with experiment.

Q20A. The structural determinants of this mutant are very close to that of the wt. As the mutation does not affect dramatically the binding, it is possible that in this case mutation is associated to rather subtle changes of the structure, which could not be captured by our models. An experimental structure and/or extensive molecular dynamics simulation on the ternary complex are required to further address this issue.

\section{Discussion}

The main purpose of this study was to investigate whether OM mutations could differentially affect OM-mediated signal transduction pathways through type I and type II receptor complexes and ultimately alter the biological responses elicited by $\mathrm{OM}$ in specific cell systems. If this is the case, one might apply structurally modified OM in treating certain disease with reduced adverse effects.

Our results from testing 14 mutants in activating ERK and STAT1 and STAT3 signaling molecules and their downstream genes have provided experimental evidence to support the feasibility of our strategy. Molecular modeling has also been performed to provide a structural basis of the effect of these mutations.

Our OM mutants were selected among the residues forming two receptor recognition sites. The first is site 3, located at the N-terminus of helix D. Site 3 is considered a distinctive feature of the gp130 cytokine family. The second is site 2, the epitope responsible for gp130 recognition (30).

The previous mutagenesis studies had defined Phe160 and Lys163 as the two key residues of site 3 for the interaction with both LIFR in type I and OSMR in type II complexes determined by proliferation assays in mouse BAF cells (30). In this study, we showed that while wt OM induced strong activation of ERK and STAT1 and STAT3 at concentrations as low as $0.25 \mathrm{ng} / \mathrm{ml}, \mathrm{K} 163 \mathrm{~A}$ mutant could not activate either signaling cascade even at $50 \mathrm{ng} / \mathrm{ml}$. Furthermore, we could neither detect changes in LDLR mRNA nor in FGB gene

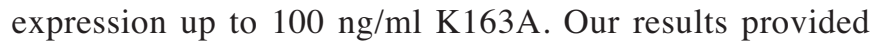
additional evidence to demonstrate the importance of Lys163 for site 3 recognition of LIFR and of OSMR.

The molecular modeling studies show that Lys163 forms an extensive $\mathrm{H}$-bond network with the cognate protein (Fig. 9A and B). Its mutation to Ala causes the disruption of such stabilizing interactions along with a rearrangement of the OM protein, which further decreases the binding. Thus, our modeling predicts that the K163A mutation causes a dramatic decrease of the affinity for both LIFR and OSMR, 
fully consistent with our experimental findings that the mutant is unable to induce the signal transductions.

The previous study has identified Asn124 and Gly120 in helix $\mathrm{C}$ being the most important residues for $\mathrm{OM} / \mathrm{gp} 130$ interaction (30). The results from this study show that mutation of glycine to alanine or to tyrosine both impaired the ability of OM to activate ERK as well as STAT1/3 signaling molecules. Consequently, OM induced transcriptional activations of LDLR and FGB were both severely compromised. Also in this case, our modeling provides a structural basis for the effect of these mutations. By changing G120 to a bulkier residue like Ala or Tyr, the D2-D3 interface of gp130 rearranges, causing a reduction of the binding affinity to both type I and type II receptor complexes (Fig. 9C).

One of the interesting findings of this study is the differential effects of Q20A and N123A on the ERK and STAT signaling pathways. Gln20 and Asn123 are both located at site 2 and were considered less critically important for $\mathrm{OM} / \mathrm{gp} 130$ interaction as compared to Gly120 and Asn124 in the previous study conducted in murine BAF cells (30). We found that these two mutants share a common characteristic of reduction in phosphorylation of STAT1 and to a lesser extent, STAT3 without losing the ability to phosphorylate ERK.

Our structural modeling suggests that the affinity N123A to type II receptor is similar to wt OM, but its binding affinity to type I is lower, because the OM rearrangement at site 3 differentially affects the H-bond networks with the two receptors. In contrast, the effect of Q20A towards LIFR might be due to rearrangement of the OM/LIFR contact surface and/or rearrangements of the OM protein. Such rearrangements could not be observed in our models. The modest reduction in LDLR transcription by Q20A and N123A could be explained by the minor contribution of type I receptor in ERK activation. Further experiments utilizing type I or type II receptor deficient cells will help to further characterize the differential roles of Gln20 and Asn123 in OM-elicited signaling pathways.

In summary, we have identified $4 \mathrm{OM}$ residues that show different involvements in OM mediated signaling through ERK and STAT pathways. Molecular modeling suggests that mutations of these residues differentially affects OM interactions with the type I and type II receptors, providing structure/function relationships for this important system.

To the best of our knowledge, this is the first study to utilize the technology of site-direct mutagenesis to modify OM with the goal to improve its therapeutic properties. These results warrant further investigations to obtain a better understanding of structure-activity relationship of human OM.

\section{Acknowledgements}

We thank Dr Najma Malik for providing the OM expression plasmid and Dr Sergio Pantano for useful suggestions. This study was supported by the Department of Veterans Affairs (Office of Research and Development, Medical Research Service, J.L.), by grant (1RO1 AT002543-01A1, J.L.) from the National Center for Complementary and Alterative Medicine and by INFM-Democritos (P.C.).

\section{References}

1. Liu J, Modrell B, Aruffo A, Marken JS, Taga T, Murakami M, Yasukawa K, Kishimoto T and Shoyab M: Interleukin-6 signal transducer gp130 mediates oncostatin M signaling. J Biol Chem 267: 16763-16766, 1992.

2. Liu J, Modrell B, Aroffo A, Scharnowske S and Shoyab M: Interactions between Oncostatin M and the IL-6 signal transducer, gp130. Cytokine 6: 272-278, 1997.

3. Taga T and Kishimoto T: Gp130 and the interleukin-6 family of cytokines. Annu Rev Immunol 15: 797-819, 1997.

4. Timmermann A, Pflanz S, Grotzinger J, Kuster A, Kurth I, Pitard V, Heinrich PC and Muller-Newen G: Different epitopes are required for gp130 activation by interleukin-6, oncostatin $\mathrm{M}$, and leukemia inhibitory factor. FEBS Lett 468: 120-124, 2000 .

5. Tanaka $\mathrm{M}$ and Miyajima A: Oncostatin M, a multifunctional cytokine. Rev Physiol Biochem Pharmacol 149: 39-52, 2003

6. Richard CD, Brown TJ, Shoyab M, Bauman H and Gauldie J: Recombinant oncostatin M stimulates the production of acute phase protein in HepG2 cells and rat primary hepatocytes in vitro. J Immunol 148: 1731-1736, 1992.

7. Heinrich PC, Behrmann I, Haan S, Hermanns HM, MüllerNewen G and Schaper F: Principles of interleukin (IL)-6-type cytokines signaling and its regulation Biochem J 374: 1-20, 2003.

8. Wang Y, Robledo O, Kinzie E, Blanchard F, Richards C, Miyajima A and Bauman $\mathrm{H}$ : Receptor subunit-specific action of oncostatin $\mathrm{M}$ in hepatic cells and its modulation by leukemia inhibitory factor. J Biol Chem 275: 25273-25285, 2000.

9. GearingDP and Bruce AG: Oncostatin M binds the highaffinity leukemia inhibitory factor receptor. New Biol 4: 61-65, 1991.

10. Gearing DP, Comeau MR, Friend DJ, Gimpel S, Thut CJ, McGourty J, Brasher KK, Kinh JA, Gillis S, Mosley B, Ziegler SF and Cosman D: The IL-6 signal transducer, gp130: an oncostatin $\mathrm{M}$ receptor and affinity converter for the LIF receptor. Science 255: 1434-1437, 1992.

11. Mosley B, Imus CD, Friend D, Boian N, Thoma B, Park L and Cosman D: Dual oncostatin M (OSM) receptors. Cloning and characterization of an alternative signaling subunit conferring OSM-specific receptor activation. J Biol Chem 271: 3263532643, 1996.

12. Plun-Favreau H, Perret D, Diveu C, Froger J, Chevalier S, Lelièvre E, Gascan $\mathrm{H}$ and Chabbert M: Leukemia inhibitory factor (LIF), cardiotrophin-1, and oncostatin M share structural binding determinants in the immunoglobulin-like domain of LIF receptor. J Biol Chem 278: 27169-27179, 2003.

13. Auguste P, Guillet C, Fourcin M, Olivier C, Veziers J, Pouplard-Barthelaix A and Gascan H: Signaling of type II oncostatin M receptor. J Biol Chem 272: 15760-16764, 1997.

14. Thoma B, Bird TA, Friend DJ, Gearing DP and Dower SK: Oncostatin $\mathrm{M}$ and leukemia inhibitory factor trigger overlapping and different signals through partially shared receptor complexes. J Biol Chem 269: 6215-6222, 1994.

15. Dekanty A, Sauane M, Cadenas B, Coluccio F, Barrio M, Casala J, Paciencia M, Rogers F, Coso OA, Piwien-Pilipuk G, Rudland PS and de Asúa LJ: Leukemia inhibitory factor induces DNA synthesis in Swiss mouse 3T3 cells independently of cyclin D1 expression through a mechanism involving MEK/ERK1/2 activation. J Biol Chem 281: 6136-6143, 2006.

16. Liu J, Spence MJ, Wallace PM, Forcier K, Hellstrom I and Vestal RE: Oncostatin M-specific receptor mediates inhibition of breast cancer cell growth, antagonism of growth factors, and down regulation of c-myc protooncogene. Cell Growth Differ 8: 667-676, 1997.

17. Liu J, Hadjokas N, Mosley B, Estro Z, Spence MJ and Vestal RE: Oncostatin M-specific receptor expression and function in regulating cell proliferation of normal and malignant mammary epithelial cells. Cytokine 10: 295-302, 1998.

18. Song HY, Kim MR, Lee MJ, Jeon ES, Bae YC, Jung JS and Kim JH: Oncostatin $\mathrm{M}$ decreases adiponectin expression and induces dedifferentiation of adipocytes by JAK3- and MEKdependent pathways. Int J Biochem Cell Biol 39: 439-449, 2007.

19. Miyaoka Y, Tanaka M, Naiki T and Miyajima A: Oncostatin M inhibits adipogenesis through the RAS/ERK and STAT5 signaling pathways. J Biol Chem 281: 37913-37920, 2006. 
20. Dierssen U, Beraza N, Lutz HH, Liedtke C, Ernst M, Wasmuth HE and Trautwein C: Molecular dissection of gp130-dependent pathways in hepatocytes during liver regeneration. J Biol Chem 283: 9886-9895, 2008.

21. Heinrich PC, Behrmann I, Muller-Newen G, Schaper F and Graeve L: Interleukin-6-type cytokine signalling through the gp130/Jak/STAT pathway. Biochem J 334 (Pt2): 297-314, 1998.

22. Zhang F, Li C, Halfter H and Liu J: Delineating an oncostatin M-activated STAT3 signaling pathway that modulates gene expression and cellular responses in MCF-7 cells. Oncogene 22: 894-905, 2003

23. Li C, Kraemer FB, Ahlborn TE and Liu J: Induction of LDL receptor transcription by oncostatin $\mathrm{M}$ is mediated by the ERK signaling pathway and the repeat 3 element of the LDL receptor promoter. J Biol Chem 274: 6747-6753, 1999.

24. Kino T, Rice KC and Chrousos GP: The PPARdelta agonist GW501516 suppresses interleukin-6-mediated hepatocyte acute phase reaction via STAT3 inhibition. Eur J Clin Invest 37 425-433, 2007.

25. Hekerman P, Zeidler J, Korfmacher S, Bamberg-Lemper S, Knobelspies H, Zabeau L, Tavernier J and Becker W: Leptin induces inflammation-related genes in RINm5F insulinoma cells. BMC Mol Biol 8: 41-45, 2007.

26. Albrecht U, Yang X, Asselta R, Keitel V, Tenchini ML, Ludwig S, Heinrich PC, Häussinger D, Schaper F and Bode JG: Activation of NF-kappaB by IL-1beta blocks IL-6-induced sustained STAT3 activation and STAT3-dependent gene expression of the human gamma-fibrinogen gene. Cell Signal 19: 1866-1878, 2007.

27. Herbert JM, Bernat A and Chatenet-Duchene L: Effect of ciprofibrate on fibrinogen synthesis in vitro on hepatoma cells and in vivo in genetically obese Zucker rats. Blood Coagul Fibrinolysis 10: 239-244, 1999.
28. Boulanger MJ, Bankovich AJ, Kortemme T, Baker D and Garcia KC: Convergent mechanisms for recognition of divergent cytokines by the shared signaling receptor gp130. Mol Cell 12: 577-589, 2003.

29. Huyton T, Zhang JG, Luo CS, Lou MZ, Hilton DJ, Nicola NA and Garrett TP: An unusual cytokine:Ig-domain interaction revealed in the crystal structure of leukemia inhibitory factor (LIF) in complex with the LIF receptor. Proc Natl Acad Sci USA 104: 12737-12742, 2007

30. Deller MC, Hudson KR, Ikemizu S, Bravo J, Jones EY and Health JK: Crystal structure and functional dissection of the cytostatic cytokine oncostatin M. Structure 8: 863-874, 2000.

31. Malik N, Kallestad JC, Gunderson NL, Austin SD, Neubauer MG, Ochs V, Marquardt H, Zarling JM, Shoyab M, Wei CM, Linsley PS and Rose TM: Molecular cloning, sequence analysis, and functional expression of a novel growth regulator, oncostatin M. Mol Cell Biol 9: 2847-2853, 1989.

32. Russell RB and Barton GJ: Multiple protein sequence alignment from tertiary structure comparison: assignment of global and residue confidence levels. Proteins 14: 309-323, 1992.

33. Sali A and Blundell TL: Comparative protein modeling by satisfaction of spatial restraints. J Mol Biol 234: 779-815, 1993.

34. Dominguez C, Boelens R, Bonvin AM: HADDOCK: a proteinprotein docking approach based on biochemical or biophysical information. J Am Chem Soc 125: 1731-1737, 2003.

35. Guex N and Peitsch MC: SWISS-MODEL and the Swiss-Pdb Viewer: an environment for comparative protein modeling. Electrophoresis 18: 2714-2723, 1997.

36. Cozzetto D and Tramontano A: Relationship between multiple sequence alignments and quality of protein comparative models. Proteins 58: 151-157, 2005. 